\title{
RESEARCH ON DISASTER EARLY WARNING AND DISASTER RELIEF INTEGRATED SERVICE SYSTEM BASED ON BLOCK DATA THEORY
}

\author{
YANG Jing ${ }^{1, *}$, ZHANG Hongping ${ }^{1}$, WANG Cong ${ }^{1}$, TANG Dejin ${ }^{1}$ \\ NGCC, No.28, Lianhuachi West Road, Haidian District, Beijing- \\ (yangjing,zhanghongping,wangcong,tangdejin)@ngcc.cn
}

Commission III, ICWG III/IVa

KEY WORDS: Block data, Disaster Early Warning, Emergency Relief, Data Fusion, Service Aggregation, TIANDITU(MapWorld)

\begin{abstract}
:
With the continuous development of social economy, the interaction between mankind and nature has become increasingly evident. Disastrous global catastrophes have occurred from time to time, causing huge losses to people's lives and property. All governments recognize the importance of the establishment of disaster early warning and release mechanisms, and it is also an urgent issue to improve the comprehensive service level of emergency response and disaster relief. However, disaster early warning and emergency relief information is usually generated by different departments, and the diverse data sources, difficult integration, and limited release speed have always been difficult issues to be solved. Block data is the aggregation of various distributed (point data) and segmentation (data) big data on a specific platform and make them happen continuous polymerization effect, block data theory is a good solution to cross-sectoral, cross-platform Disaster information data sharing and integration problems. This paper attempts to discuss the integrated service mechanism of disaster information aggregation and disaster relief based on block data theory and introduces a location-based integrated service system for disaster early warning and disaster relief.
\end{abstract}

\section{INTRODUCTION}

With the continuous development of social economy, the interaction between mankind and nature has become increasingly evident. Disastrous global catastrophes have occurred from time to time, causing huge losses to people's lives and property. All governments recognize the importance of the establishment of disaster early warning and release mechanisms, and it is also an urgent issue to improve the comprehensive service level of emergency response and disaster relief. Internationally, various countries have established disaster warning and emergency response mechanisms appropriate to their national conditions. In order to deal with frequent disasters, the U.S. government has established an Emergency Alert System (EAS) that uses radio and television transmission coverage to provide emergency information services to the public in the United States. Since its launch in 1997, EAS has never been launched nationwide. A presidential notice was issued, but at the state and local levels, governments at all levels have been using it to publish major meteorological disasters and find regional emergency information such as missing children (LI Xiaobei, 2016). Japan is one of the most vulnerable places in the world to natural disasters. As early as 2006, the Japanese government established an earthquake and tsunami warning system, a volcano early-warning information release system, and a severe weather disaster early warning system that can observe and publish disasters in real time. Early warning information and comprehensive utilization of various types of information (YAO Guozhang,2007)。China has a vast territory and complex geographical conditions. Many places are also affected by serious natural disasters and dangers. Since the $21 \mathrm{st}$ century, China's major disasters have occurred frequently (ZHOU Limin et_al.,2017). After many years of construction, China's natural disaster early warning system has taken shape. It has played an important role in providing emergency decisions for the government and safeguarding of people's lives and properties. However, compared to other leading countries, our country has effectively improved disaster warning capabilities and There are also many problems and difficulties in improving the level of emergency esponse. Among them, the timely collection of emergency warning information and the release of comprehensive information are currently urgent problems to be solved. However, disaster early warning and emergency relief information is usually generated by different departments, and the diverse data sources, difficult integration, and limited release speed have always been difficult issues to be solved. China's meteorology, earthquake and other departments all have the ability to observe and release disaster warning information, but so far there has not been a unified platform for the collection of all types of emergency disaster warning, and then provides comprehensive support for emergency disaster recovery decision management.

Block data is the aggregation of various distributed (point data) and segmentation (data) big data on a specific platform and make them happen continuous polymerization effect, block data theory is a good solution to cross-sectoral, cross-platform Disaster information data sharing and integration problems. This paper attempts to discuss the integrated service mechanism of disaster information aggregation and disaster relief based on block data theory and introduces a location-based integrated service system for disaster early warning and disaster relief.

\section{DISASTER WARNING AND EMERGENCY RESPONSE INFORMATION SYSTEM}

The first part of the article will summarize and sort out the available early warning information and its classification and

\footnotetext{
* National Key R\&D Program Of China (No.2017YFB0503700) yangjing@ngcc.cn;Phone:13466721701
} 
establish a complete system. Disaster early warning information refers to information that is of guiding significance to emergency disaster relief before a disaster, such as the possible disasters, its social impact and the establishment of an emergency network Emergencies. It generally includes natural disasters, accident disasters, public health incidents, security incidents, and other emergencies. The disaster early warning information mentioned in this paper mainly focuses on the early warning of natural disasters. Natural disasters mainly include meteorological disasters such as high temperature and drought, geological disasters such as mountain collapse, landslides and mudslides, marine disasters such as tsunami, earthquake disasters, and forest and grassland fires. Disaster early warning information usually include disaster event information(disaster type, duration, intensity, etc.), influence information( disaster area, potential loses and other disaster, etc.) and emergency relief information( emergency shelter, rescue forces, etc.). On this basis, according to the national information classification and coding standard of the national emergency platform system issued by China, emergency response information can include emergency information (natural disasters, accidents, public health events, and security incidents), hazard sources, and risk hidden danger areas. (Including hidden danger areas of natural disasters, sources of accidental disasters, sources of public health hazards, and hidden dangers of social security), protective targets (important parts, critical infrastructure, and other protective targets), emergency information safeguard resources (emergency agencies, emergency human resources, Emergency supplies, emergency communications resources, emergency transport and logistics resources, medical and health resources, emergency shelter areas, and emergency financial resources) and emergency knowledge (laws, regulations, technical specifications, and others), etc.

\section{INFORMATION INTEGRATION METHOD BASED ON BLOCK DATA}

\subsection{Block Data Theory}

Based on the block data theory, the second part of this article introduces the integration including disaster event information (disaster type, location, duration, intensity, etc.), influence information (disaster area, potential losses and other Disaster, etc.) and emergency relief information (emergency shelter, rescue forces, etc.)rated utilization of multi-source heterogeneous disaster information on the same platform under the existing system. Big data emphasizes the application of mathematical algorithms on processing massive data to predict the ability of things to happen. It is a result of high development of data, technology and thinking (Mayr-Schönberger, V. et al., 2013). But so far, the big data that humans have formed are more often organized within a certain domain or industry. These data are often fragmented and incommunicable (Big Data Strategy Key Laboratory, 2015). In 2015, Big Data Strategy Labs creatively proposed the concept of "block data" (Big Data Strategy Key Laboratory, 2017) , Block data is a continuous aggregation of highly correlated data of various types on a specific platform. Through data association analysis, the goal of discovering new knowledge, creating new value and improving new capabilities is realized (Big Data Strategy Key Laboratory, 2016). The block data can overcome a series of constraints such as sharing difficulties, industry monopoly, poor integration, low level of application and high security risk etc. that are faced with the development of big data in the "period of the era", so as to avoid the bottleneck problems generated from disaster early warning and the comprehensive use of emergency response information such as data barriers, information independence, and poor integrated service capabilities make a variety of information related to each other and thus generate greater value. The aggregation effect of block data can be used to make more rapid, more comprehensive, more accurate and more effective judgments and predictions of things through multidimensional data fusion and correlation analysis, thereby revealing the essential laws of things (LIAN Yuming,2017). Applying the block data theory to disaster warning and emergency response information release, public service, and government strategic decision-making will help break the data cage independently maintained by various types of information, optimize the allocation of government resources, and improve the service effectiveness of information distribution agencies at all levels, and also promote the integration, sharing, and utilization of all kinds of information.

\subsection{Two information integration methods}

This paper argues that the disaster information is mostly related to the spatial location, so the correlation between various disaster information must be based on the spatial and geographical information. According to block data theory, there are mainly two modes to integrate and publish disaster early warning information: data center mode and online calling mode. The data centre mode establishes disaster information database through offline data integration, online data submission and online data crawling, and then activate the association between data to form a portfolio of information with multiple values. On one hand, the data center brings together multi-source data. On the other hand, because it owns the data itself, it can integrate and use the data, research and analysis, and information reengineering, fully mine the value of the data, and use different sources and structures on a unified platform to produce greater application value. At the same time, to establish a data centre requires a lot of manpower, material resources, and financial resources on integrated using data, the safe maintenance of information has become an important factor restricting the continuous use of data centre. Therefore, the online service integration model is called for compensating the "dead data" deficiencies and makes the data "active". Online calling mode is online collection of scattered in the local database stored in various departments, through the way of service access, based on certain rules to remotely call these scattered information, and make them an organic whole of the service, resulting in greater value. Since the disaster warning information is mostly realtime information, it is usually maintained and released in separate business environments and business systems of different departments. In the event of a disaster, the disaster warning information needs to be brought together for the first time to provide the basis for government decision-making and disaster relief. Therefore, online calling Mode more in line with the basic needs of emergency, and data center model better meet the needs of emergency disaster relief and decision-making such as comprehensive analysis.

\section{DISASTEREARLYWARNING AND EMERGENCY RESCUE COMPREHENSIVE SERVICE SYSTEM PRACTICE BASEDON MAPWORLD PLATFORM}

\subsection{System Introduction and MapWorld}

This paragraph introduces the comprehensive service system of disaster early warning and disaster relief generated from MapWorld platform. The emergency response and disaster 
relief integrated service system described in this paper is contributed according to the two types of information integration model based on block data theory. Relying on the existing MapWorld platform, this system support existing resources adopts a combination of data aggregation and service integration and brought together all types of disaster warnings and emergency response information in a maximal manner to provide services to the government and the public in an objective, accurate, and real-time manner. National Geographic Information Public Service Platform "MapWorld" is a networked geographic information sharing and service platform led by the National Bureau of Surveying and Mapping Geographic Information. (HUANG Wei,2014), it integrates geographic information resources from the national, provincial and city (county) levels of surveying and mapping geographic information departments, as well as relevant government departments, enterprises and institutions etc., and provide authoritative, standard, unified online geographic information services through the Internet, national e-government extranets, and national e-government intranets. In the long-term practice of emergency relief work, the MapWorld has gradually formed a solid emergency mapping geographic information service support capabilities, formed a set of technical processes on disaster warning information, dynamic acquisition, storage, integrated application and dynamic release. The design and implementation of this system is based on this kind of technology. The purpose is to realize multi-source disaster warning and cross-platform integrated utilization and information release of emergency disaster information on the map of the sky.

The system is deployed in the national e-government intranet. Based on the national government geographic information, the system integrates emergency special information such as disaster relief resources and early warning information to realize disaster Early warning and emergency relief integrated services support. This system integrates information including three categories of basic geographic information, disaster warning information, and emergency response resources. The basic geographic information includes the results of the national geographic information public service platform MapWorld (digital line maps, remote sensing images, topographic maps, and Geographic names address), a series of major construction projects construction achievements (National 1:5000 basic geographic information database update and geographic national conditions monitoring, etc.), etc. These information come from the surveying and mapping geographic information department itself. The disaster warning information includes hazard sources and risk information, earthquake risk areas, key protection targets, national daily rainfall monitoring information, and earthquake warning information. The emergency rescue resources information includes water infrastructure and emergency protection resources, and some of these information come from The business construction data of the relevant ministries and commissions of the State Council, some are derived from the specialization and integration of the existing basic geographic information of the surveying and mapping department, and others are from the integrated analysis of the business data of the ministries and commissions and the basic geographic information data.

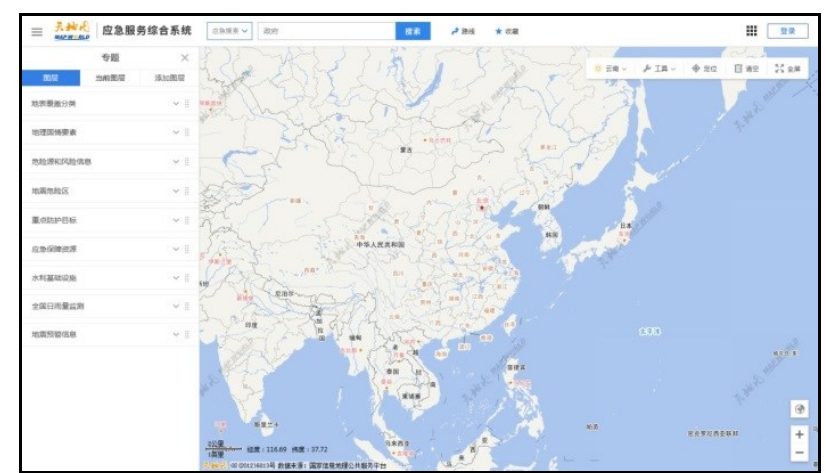

Figure 1. Disaster early warning and emergency rescue comprehensive service system screenshot

\subsection{System Structure and Functions}

The system adopts the SOA architecture and the overall structure includes infrastructure, data layer, application support layer, service layer and presentation layer. Infrastructure layer mainly refers to those equipment and environment, such as cloud infrastructure, software and hardware, safety equipment and national e-government network. It is worth mentioned that resources can only be integrated in a unified network environment, some useful information are difficult to integrate and use because of separated network and copy difficulties. Data layer including basic information database and geographic information service. Considering about the information resources and its classification in this system, three databases were established: basic database, the geographic information basic database mainly store national geographic information public service basic data, while disaster early warning and relief information from Ministry of Water Resources and other government departments are saved in the emergency thematic database. Some information produced by analysing comprehensively the two kinds of resources above is kept in the derivative information database. On the other hand, some basic geographic information support the whole applications of this system in the form of services, some of them generated from a series of major geographic project such as National 1:50000 Base Map Database Update and National Geographic conditions monitoring, others are got from different departments. Some function model are aggregated and utilized to support the system and constitute collaboratively the application support layer. There are three of main function model, data management, service management and website management. Data management module includes data conversation, data processing, symbol configuration and database registration and management. Services are released, surrogate and monitoring dynamically in the services management module. Website is the client's manifestation of this system, therefore some functions are developed to customize the website, release information, generate and manage directory and monitoring the website. Service layer is constituted by map service, data service, application service and analysis service, which accomplish the goal of aggregating and using multi-source information in the form of services. The results of the construction of all systems are represented by thematic websites and numerous service interfaces. Last but not least, the whole system are created based on a series of standard specification of different industries and safe operation and maintain mechanism. 
The main functions of this system include basic map browse (searching, route planning) and query, disaster information release, map tools (measurement, online plotting, sharing, printing, plotting), spatial statistics and analysis.

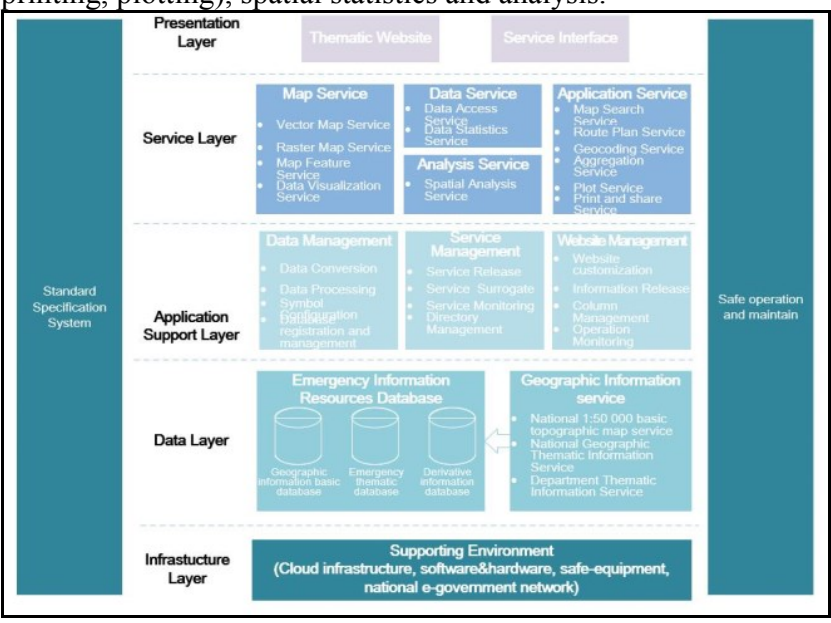

Figure 2. System structure

\subsection{Techinacal Realization}

Based on the existing construction results of the MapWorld Platform, the system forms the basic database of administrative geographic information through the integration of the basic geographic information data and the thematic data fusion of the government affairs. Through data capture, data exchange and integration, the system forms a comprehensive database of emergency disaster relief, meet the application requirements of base map browsing, query, statistical analysis, etc.; Water conservancy project information (hydropower stations, dams, etc.), rainstorm warning information, earthquake warning information and extreme weather warning information access to the system through service aggregation. By taking advantage of the service interfaces provided by relevant departments, the service are parsed, matched and forwarded, so that these information in a few independent business systems and updated in real time collected to the system platform on time; Simultaneously, Disaster information data from users are collected and distributed through online mapping and online service upload. In a word, this system achieve the aggregate expression, integration and application of rapid service of disaster early warning and disaster prevention and mitigation information on the same platform, and provides reference to the unified emergency used map projection.

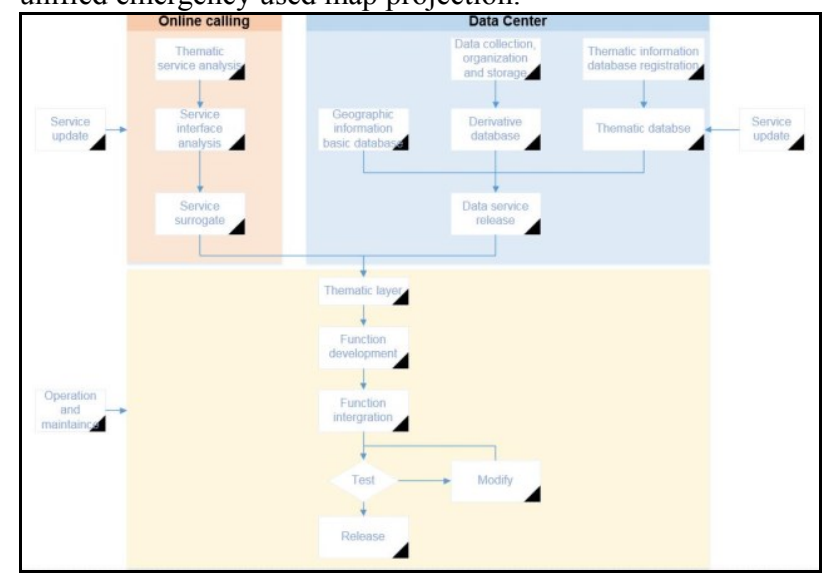

Figure 3. System technical route

\section{SUMMARY}

To sum up, China's disaster warning and emergency response work still lacks long-term system construction and mechanism building. Information barriers still exist in various departments, and the integration and utilization of multiple information are still difficult. Applying block data theory to separate the use rights and ownership of data can promote the open sharing of data resources in emergency response areas, break down data trails and data monopolies, and establish a new order for disaster warning and emergency response information sharing and integration. The disaster early warning and emergency response integrated service system introduced in this paper utilizes the limited data resources that can be integrated in the egovernment extranet environment. Through the combination of data fusion and service aggregation, various types of information are efficiently collected and passed. The support of system functions enables these information to be aggregated and related to each other, activating the entire information system, providing support for the release of disaster warning information, decision-making for emergency response and disaster response, and the formulation of relevant strategies. It also provides technical demonstrations for maximizing the integration and utilization of information in this field.

\section{REFERENCES}

LI Xiaobei, 2016. The operation characteristics of u.s. Emergency warning system and comparison with china's emergency broadcasting system. China Emergency Management, 2016(9), pp. 79-82.

YAO Guozhang, 2007. Japan natural disaster early warning system construction report. E-government, 2007(11), pp. 67-82.

ZHOU Limin, LONG Zhiguang, 2017. Disaster early warning innovation in the era of big data_taking yangjiang emergency warning information distribution centre as a case. Journal of Wuhan University(Philosophy and Social Science Edition), 70(3), pp.121-132.

Mayr-Schönberger, V., Cooke, K., SHENG Yangyan, 2016. Big Data Era. Sales and Marketing(Comment Edition), 8(10), pp. 27-31.

Big Data Strategy Key Laboratory, 2015. Block Data 1.0: Signs Of Big Data Really Arrival. CITIC Publishing House, pp. preface.

Big Data Strategy Key Laboratory, 2017. Block Data 3.0: Order Internet And Sovereign Block Chain. CITIC Publishing House, pp.178.

Big Data Strategy Key Laboratory, 2016. Block Data 2.0: The Paradigm Revolution in the Era Of Big Data. CITIC Publishing House, pp. 31-35.

LIAN Yuming, 2017. Redefining Big Data. Machinery Industry Press, pp. 27.

HUANG Wei, 2014. National Geographic Information Public Service Platform MapWorld. Satellite Applications, 2014(1), pp. 41-44. 